\title{
Seismic Analysis of Cultural Heritage Structure in Mandalay City
}

\author{
Pyin Sa Oo, and Dr.Aye Mya Cho
}

\begin{abstract}
Recent earthquakes in Myanmar have underlined the need for wide monitoring and safety assessment of cultural heritage structures. The study investigates the seismic vulnerability of a specific monumental masonry structure: the main stupa of Kuthodaw Pagoda in Mandalay. The required experimental tests are conducted to determine the material properties of the structure. The vibration characteristics of the structure are determined by performing modal analysis. Then, the probabilistic seismic hazard analysis is done to get ground motion data consistent with local seismic conditions. These seismic waves are used for the input of time history analyses. Comparisons of the expected seismic demand and the seismic capacity of the structure are done to determine the weak parts of the structure under earthquakes. The results have shown that the top of the pagoda is very sensitive to the seismic waves. It is deformed significantly, and the structure is damaged by over-tensioning. Retrofitting should be planned to improve the seismic resistance of these parts by means of appropriate techniques.
\end{abstract}

Keywords - Cultural Heritage Structures, Mandalay, Modal Analysis , Time History Analyses

\section{INTRODUCTION}

Heritage structures perform vital role in nation's history, culture and signify the richness of it. To augment life and enhance strength, their restoration is very important for the future generations to have knowledge about how mankind lived in past ages. The majority of the main structural systems for historical heritage structures or monuments are masonry elements, composed of stone, bricks and mortar. For all types of old historical masonry structures erected in seismic zones of high seismicity, earthquake is always their number one "enemy" due to their very bad response to earthquakes.

Earthquake is one of natural phenomenon which cannot be accurately predicted where and when it will happen. Since earthquake force intensity changes with time, then its effect to the structure also changes with time. Unlike the common static load, earthquake waves randomly propagate, hence the effect at the structure response cannot be easily determined. Structure only carries dead load and live load at the static condition. Earthquakes act as non-harmonic, non-periodic and

Manuscript received Nov.7, 2016.

Pyin $\mathrm{Sa}$ Oo is a PhD candidate in Civil Engineering Department, Mandalay Technological University, Myanmar

Dr.Aye Mya Cho is an Associate Professor in Civil Engineering Department, Mandalay Technological University, Myanmar non-stationary dynamic load in the form of wave radiation from the source. The wave is then radiated in all directions with the surrounding soil and rocks medium until approaching earth surface and causing vibration. Ground motion received by foundation is then continued to the upper structure, resulting in oscillation at the building as inertial forces.

Recently, it was observed that the frequency of occurrences of earthquakes along the Sagaing fault has increased. Though an earthquake could not be prevented, the loss of life and damage to property could be minimized. Steps could be taken to reduce the damages to existing structures. The estimation of the seismic vulnerability of a heritage structure is a multi-phased process that ranges from the description of earthquake sources to the characterization of structural response, and to the description of measures for seismic protection.

Myanmar is prone to great earthquakes. In 1917, Bago earthquake hit Bago region causing failure of top portion of the Shwemawdaw Pagoda. Recently, the magnitude of 6.8 earthquake struck Myanmar $25 \mathrm{~km}$ west of Chauk with a maximum Mercalli intensity of VI and several pagodas and temples in the nearby ancient city of Bagan were damaged. The failures of the structures exampled above indicate seismic vulnerability of the heritage structures and evaluation for seismic safety and strengthening are extremely needed. The present study illustrates the procedure for nonlinear seismic analysis of masonry building using ANSYS software [1]. The analysis can also check whether retrofitting of the existing structure is required or not. Some damages of heritage structures during past earthquakes can be seen in Fig. 1.
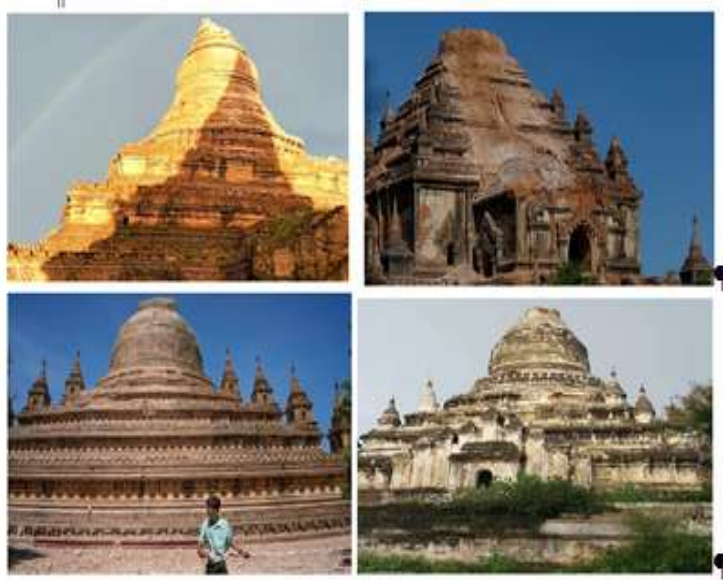

Fig.1 Earthquake damages of heritage structures 


\section{History AND DESCRIPTION OF STUDY AREA}

In this study, the main stupa of Kuthodaw Pagoda shown in Fig. 2 was selected as a case study. The Kuthodaw Pagoda or Maha Lawka Marazein Paya is a Buddhist stupa, located in Mandalay, Myanmar, that contains the world's largest book. It is a brick masonry structure. It earned the title of the biggest book in the world thanks to the 729 slabs stored in small pagodas called Dhammazedis. Literally, each Dhammazedi means a lesson of Gautama Buddha. It is a large walled complex situated at the base of the southeast stairway to Mandalay Hill and was built by King Mindon at the same time he was constructing the Royal Palace. Its central stupa is modelled on the Shwezigon at Nyaung $U$ near Bagan. According the an on-site stela, the central stupa of Maha Lawka Marazein Paya is 187 feet high, including the platform on which it stands, while some guide books usually list its net height as 100 feet high.

The stupa itself, connected to the outside entry by means of a long corridor, is set in the middle of a thirteen acre field of 729 kyauk sa gu or stone-inscription caves. Each contains a marble slab inscribed on both sides with a page of text from the Tipitaka. The marble was quarried from Sagyin Hill 32 miles north of Mandalay, and transported by river to the city. Work began on 14 October 1860 in a special hall within King Mindon's Royal Palace. The text had been meticulously edited by tiers of senior monks and lay officials consulting the Tipitaka kept in royal libraries in the form of peisa or palm leaf manuscripts. Scribes carefully copied the text on marble for stonemasons. Each stone has 80 to 100 lines of inscription on each side in round Burmese script, chiselled out and originally filled in with gold ink. It took a scribe three days to copy both the obverse and the reverse sides, and a stonemason could finish up to 16 lines a day. All the stones were completed and opened to the public on 4 May 1868. Each slab is 5 feet high, 3.5 feet wide and 5-6 inches thick. If spread out horizontally, the slabs would cover a third of an acre, stacked vertically, the 'pages' would rise 340 feet.

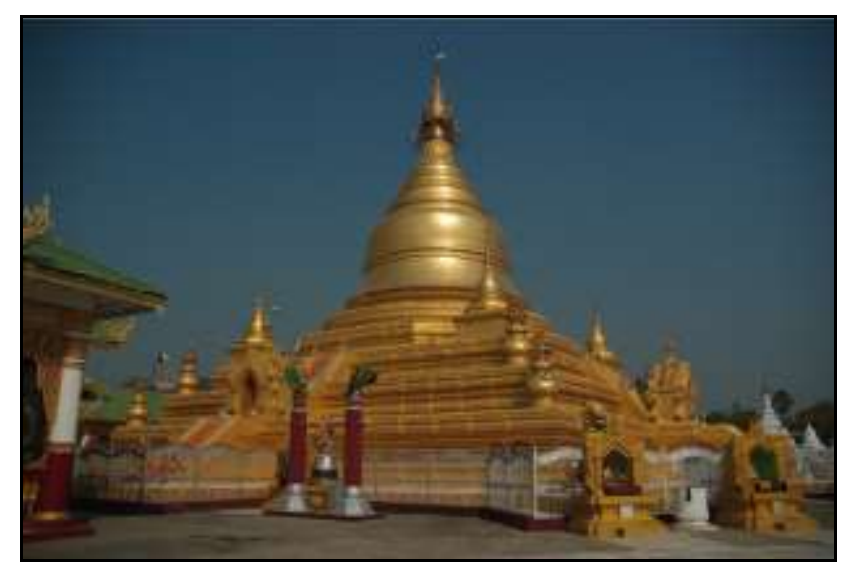

Fig. 2 Main stupa of Kuthodaw Pagoda

\section{Methodology}

In this study, the nonlinear seismic analysis of case studied structure is carried out using time-history analysis using
ANSYS software [1]. The experimental tests are conducted to determine the existing properties of the materials. The case studied masonry structure is modeled and then the model is meshed. The vibration characteristics of the structure are determined by performing modal analysis. Then transient analysis of the structure is performed considering the appropriate seismic loading and the results are compared with the permissible values. The general methodology used in this study is illustrated in Fig. 3.

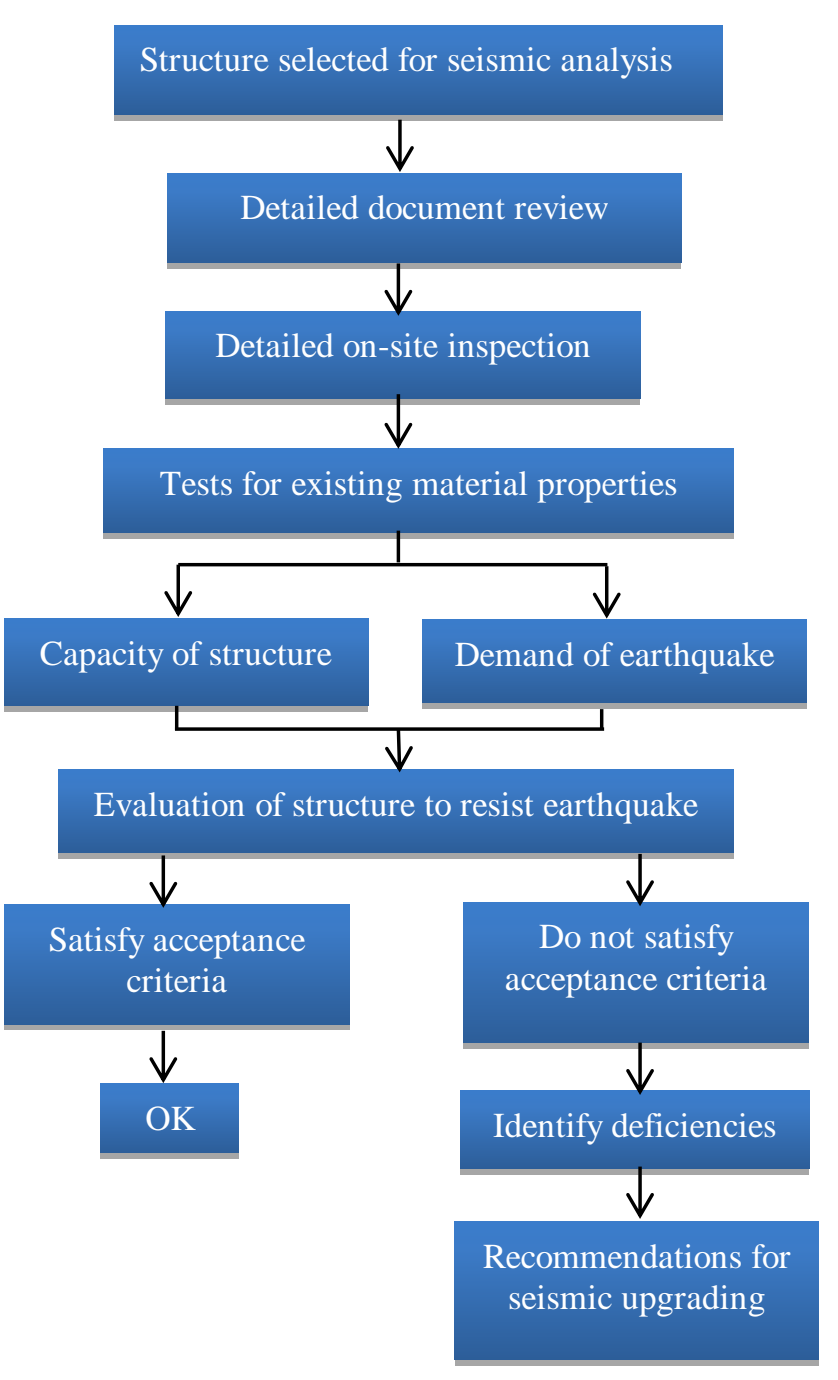

Fig. 3 Flow chart of the general methodology

\section{Case Study of Cultural Heritage Structure}

\section{A. Finite Element Model}

The case studied structure selected in this study is Kuthodaw Pagoda located in Mandalay. It is one of the structures listed on the Memory of the World Register of the UNESCO. It is the brick masonry structure. It has five terraces: three are square shaped, one is polygonal shaped and one is circular shaped. Overall height is $30.5 \mathrm{~m}$ excluding the height of umbrella. The required experimental tests are conducted to determine the existing properties of the materials. Material properties used in the analysis are tabulated in Table 1. 
TABLE I

MATERIAL PROPERTIES

\begin{tabular}{lc}
\multicolumn{1}{c}{ Properties } & Masonry \\
\hline Unit weight $\left(\mathrm{kg} / \mathrm{m}^{3}\right)$ & 1677.6 \\
Young modulus $(\mathrm{Pa})$ & $2.511 \times 10^{6}$ \\
Poison's ratio & 0.25 \\
Ultimate compressive strength (MPa) & 3.348 \\
Ultimate tensile strength (MPa) & 0.512 \\
\hline
\end{tabular}

The three dimensional finite element model of the proposed structure is prepared by using ANSYS software. The model is comprised of 3,358 solid elements with 23,242 nodes. The plan view and finite element model of the proposed structure is illustrated in Fig. 4.

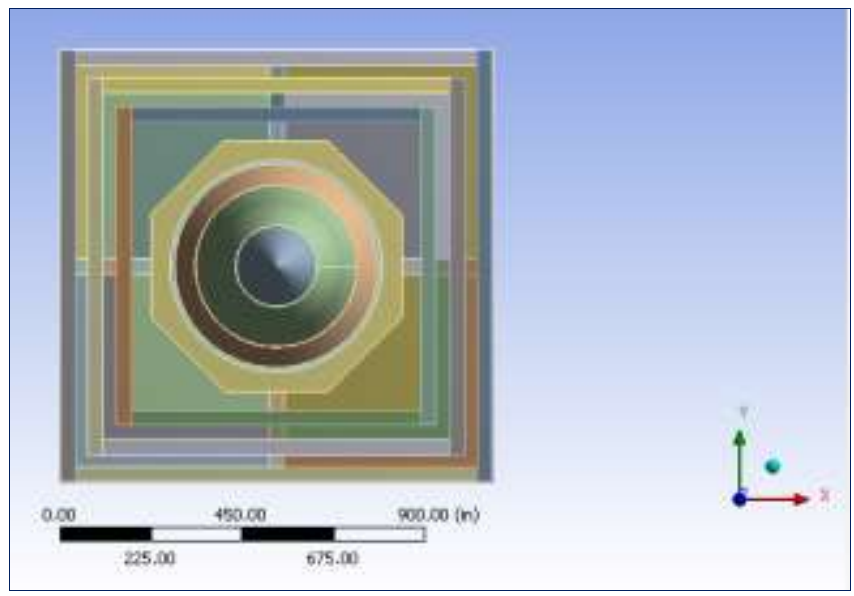

(a)

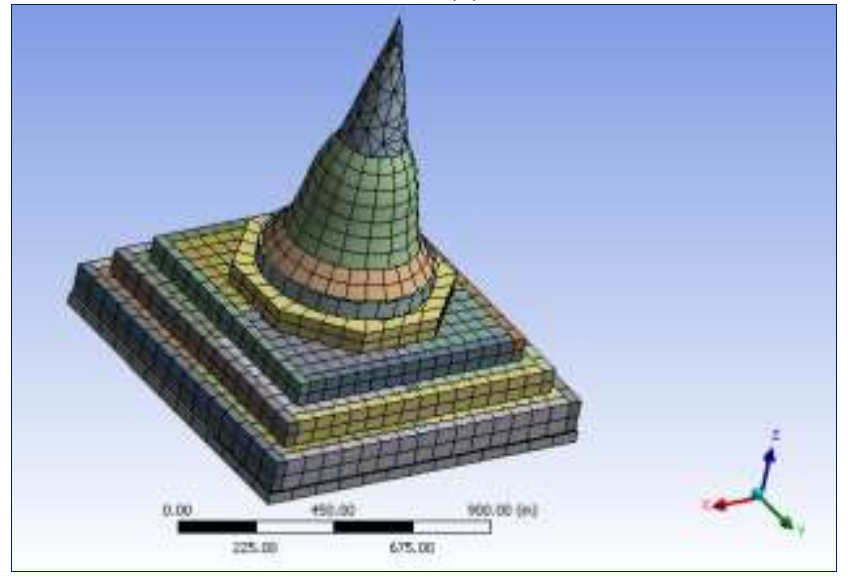

(b)

Fig. 4 Proposed structure; (a) Plan view (b) Finite element model

\section{B. Seismic Hazard Levels}

An earthquake level is defined with a probability of being exceeded in a specified period. The following three levels are commonly defined for buildings with a design life of 50 years [2]:

1. Serviceability Earthquake (SE),

2. Design Basis Earthquake (DBE), and
3. Maximum Considered Earthquake (MCE).

The definitions of the SE, DBE, and MCE defined by the ATC-40 are as follows:

The Serviceability Earthquake (SE) is defined probabilistically as the level of ground shaking that has a $50 \%$ chance of being exceeded in a 50-year period.

The Design Basic Earthquake (DBE) is defined probabilistically as the level of ground shaking that has a $10 \%$ chance of being exceeded in a 50-year period.

The Maximum Considered Earthquake (MCE) is defined probabilistically as the level of ground shaking that has a $2 \%$ chance of being exceeded in a 50-year period.

Mostly, the seismic hazard levels are determined by the probabilistic seismic hazard analysis (PSHA) [5]. Seismic hazard analysis involves estimation of ground motion hazard at a particular area. The following three steps are generally required in the PSHA:

1. Specification of the seismic hazard source model,

2. Specification of the ground motion model, and

3. The probabilistic calculation

1) Seismic Hazard Source Model: The seismic-hazard source model is a description of the magnitude, location, and timing of all earthquakes. In this study, the estimation seismic hazard levels are based on the seismic hazards assessment for Myanmar developed by Myanmar Earthquake Committee (MEC) and Myanmar Geosciences Society (MGS) [8] and bounded Gutenberg-Richter recurrence law. The cumulative distribution function for magnitude of an earthquake can be described as follows [5].

$$
\mathrm{F}_{\mathrm{M}}(\mathrm{m})=\frac{1-10^{-\mathrm{b}\left(\mathrm{M}-\mathrm{M}_{\min }\right)}}{1-10^{-\mathrm{b}\left(\mathrm{M}_{\max }-\mathrm{M}_{\min }\right)}}
$$

where

$\mathrm{F}_{\mathrm{M}}(\mathrm{m})=$ the cumulative distribution function for $\mathrm{M}$

$\mathrm{b} \quad=$ seismic constant

$\mathrm{M}_{\min } \quad=$ minimum magnitude

$\mathrm{M}_{\max } \quad=$ maximum magnitude

The probabilities of occurrence of discrete set of magnitudes are computed by the following equation [5].

$$
P\left(M=m_{j}\right)=F_{M}\left(m_{j+1}\right)-F_{M}\left(m_{j}\right)
$$

where $m_{j}$ are the discrete set of magnitudes. Annual rate of exceedance of certain earthquake magnitude for the Sagaing fault shown in Fig. 6 is developed by using the seismic historical data of the Sagaing Fault [8] illustrated in Fig. 5 and Table 2. 


\begin{tabular}{|c|c|c|c|c|c|c|c|c|c|c|c|}
\hline Kant & Sthrosact & $\mathrm{Coc}$ & $\operatorname{sen} x_{3}$ & $\mathrm{CoOr}$ & trentes & $\mathrm{N}$ & $\mathrm{N}_{\mathrm{gn}}$ & $b$ & 3 & $i$ & $\mathrm{~F}$ \\
\hline \multirow{8}{*}{$\begin{array}{l}\text { Yodal: } \\
\text { Segant } \\
\text { of } \\
\text { Saging } \\
\text { fall }\end{array}$} & sassoen scti & 95359 & $254 !$ & 59563 & 2259 & 5 & 76 & 0624 & 15789 & 02535 & $\mathrm{~N}$ \\
\hline & & 9537 & 21356 & $5 \mathrm{cos}$ & $21 \times 6$ & & & & & & \\
\hline & SGssan sco: & 95952 & 215 & sका & 21.74 & 5 & 79 & 0,54 & 15759 & 02535 & N \\
\hline & & 95399 & 2059 & 32032 & 2556 & & & & & & \\
\hline & sassand_scti & 9603 & 20551 & 9605 & W5st & 5 & 78 & 0684 & 15759 & 02535 & $\bar{M}$ \\
\hline & & $-96: 47$ & จาะ & $351 ?$ & 1978 & & & & & & \\
\hline & sasyde scol & 96143 & 5736 & 5216 & 1974 & 5 & 77 & 0634 & $157 \times$ & 02555 & $\$$ \\
\hline & & 96234 & 13839 & sh32.2 & 18886 & & & & & & \\
\hline \multirow{8}{*}{$\begin{array}{l}\text { Soren } \\
\text { Seyent } \\
\text { of } \\
\text { Yyorrer }\end{array}$} & Scsus_ot & 96313 & 18156 & $\$ 6338$ & 38812 & $\overline{5}$ & 78 & 06535 & 14587 & (2III) & $\bar{W}$ \\
\hline & & 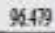 & 17748 & 96512 & 1774 & & & & & & \\
\hline & SGSU 02 & $x+25$ & 1779 & 9651 & 17788 & 5 & 76 & 06555 & 14587 & 0.1112 & $\mathrm{~N}$ \\
\hline & & $96+57$ & 17007 & 35500 & 1716 & & & & & & \\
\hline & SGQVS 03 & $96+86$ & II6: & 32.85 & 17006 & $\overline{5}$ & 76 & 06535 & 1458 & Q.111? & $\bar{W}$ \\
\hline & & $9 x+22$ & 1659 & 96.455 & 1629 & & & & & & \\
\hline & SCSQS.04 & 95515 & 15565 & \%5.458 & 1552 & 5 & 76 & 0.6335 & 1457 & QIIII) & $\mathrm{N}$ \\
\hline & & $86+77$ & 15139 & 96.46 & 16238 & & & & & & \\
\hline
\end{tabular}

Fig. 5 Seismic source parameters for Sagaing Fault

TABLE II

MAGNITUDE PROBABILITIES FOR SAGAING FAULT

\begin{tabular}{ccc}
$\mathrm{m}_{\mathrm{j}}$ & $\mathrm{F}_{\mathrm{M}}\left(\mathrm{m}_{\mathrm{j}}\right)$ & $\mathrm{P}=\left(\mathrm{M}=\mathrm{m}_{\mathrm{j}}\right)$ \\
\hline 5 & 0 & 0.4381 \\
5.25 & 0.4381 & 0.2464 \\
5.5 & 0.6845 & 0.1385 \\
5.75 & 0.823 & 0.0779 \\
6 & 0.9009 & 0.0438 \\
6.25 & 0.9447 & 0.0246 \\
6.5 & 0.9693 & 0.0139 \\
6.75 & 0.9832 & 0.0078 \\
7 & 0.991 & 0.0044 \\
7.25 & 0.9954 & 0.0025 \\
7.5 & 0.9978 & 0.0014 \\
7.75 & 0.9992 & 0.0008 \\
8 & 1 & 0 \\
\hline
\end{tabular}

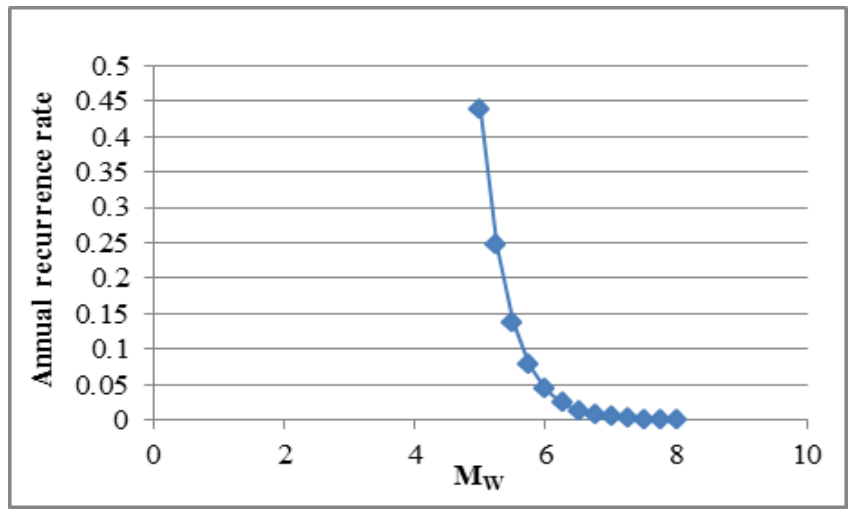

Fig. 6 Annual rate of exceedance of certain earthquake magnitude for the Sagaing fault

2) Ground Motion Model: The ground motion model used in PSHA is referred to as attenuation relationship. The most basic attenuation gives the ground motion level as a function of magnitude and distance, but may have other parameter to allow for a few different site type or style of faulting.

Cornell, et al. (1979) proposed the following predictive model for the mean of log peak ground acceleration (in units of g).

$$
\operatorname{lnPGA}=-0.152+0.859 \mathrm{M}-1.803 \ln (\mathrm{R}+25)
$$
where,
$\mathrm{R}=$ distance from the source in kilometer

3) Probabilistic Calculation: The return period, $T$ is defined as according to the following equation.

$$
\mathrm{T}=\frac{1}{\mathrm{p}}
$$

For example, a 500 years earthquake has an annual probability of exceedance of 0.002 .

The probability of an earthquake with a return period of $\mathrm{T}$ being exceeded in $\mathrm{n}$ years is given as:

$$
\mathrm{p}=1-\left(1-\frac{1}{\mathrm{~T}}\right)^{\mathrm{n}}
$$

In the UBC code, earthquake codes are based on a probability of exceedance of $10 \%$ in 50 years (i.e., $\mathrm{p}=0.1, \mathrm{n}=50$ years (i.e., $\mathrm{p}=0.1, \mathrm{n}=50$ years). The return periods of three levels of earthquakes can be calculated by Equation 5 .

The probability of occurrence in any year for the SE is, therefore, $\mathrm{p}=\frac{1}{72}=0.0139$. The probability of occurrence in any year for the DBE and MCE are 0.0021 and 0.0004 respectively. Then the associated magnitudes for the three levels of earthquakes can be assumed using Fig. 6. Finally, the peak ground accelerations (PGA) can be estimated using Equation 3 with the nearer source distance of $25 \mathrm{~km}$ from the major cities such as Yangon and Mandalay. Using those data, the estimated magnitudes for the three seismic hazard levels can be provided shown in Tale 3 .

\begin{tabular}{ccc|cc}
\multicolumn{5}{c}{ TABLE III } \\
ESTIMATED SEISMIC HAZARD LEVELS \\
$\begin{array}{c}\text { Earthquake } \\
\text { Type }\end{array}$ & $\begin{array}{l}\text { Return } \\
\text { Period, } \\
\text { T (year) }\end{array}$ & $\begin{array}{c}\text { Probability } \\
\text { in any year }\end{array}$ & $\begin{array}{c}\text { Estimated } \\
\text { Magnitude, } \\
\text { Mw }\end{array}$ & $\begin{array}{c}\text { Peak Ground } \\
\text { Acceleration, } \\
\text { PGA }\end{array}$ \\
\hline SE & 72 & 0.0139 & 6.5 & $0.2 \mathrm{~g}$ \\
DBE & 475 & 0.0021 & 7.3 & $0.4 \mathrm{~g}$ \\
MCE & 2475 & 0.0004 & 7.8 & $0.6 \mathrm{~g}$ \\
\hline
\end{tabular}

\section{Modal Analysis}

Modal analysis provides the vibration characteristics (natural frequencies and mode shapes) of a structure. In ANSYS, a modal analysis is also the starting point for other, more detailed, dynamic analysis, such as harmonic response or a transient analysis. The natural frequencies and mode shapes are important parameters in the design of a structure for dynamic loading conditions. Modal analysis in ANSYS is a linear analysis. Any nonlinearity, such as plasticity and contact (gap) elements, are ignored even if they are defined [1]. When a structure vibrates, it oscillates according to some form. Any typical system has an infinite number of modes. Such modes can be compared to some basic modes, or fundamental modes. The first three modes are the fundamental modes. They are generally the most important, as they most stress the structure [1]. The first three mode shapes and natural frequencies of the proposed structure are shown in Fig.7 and Table 4. 


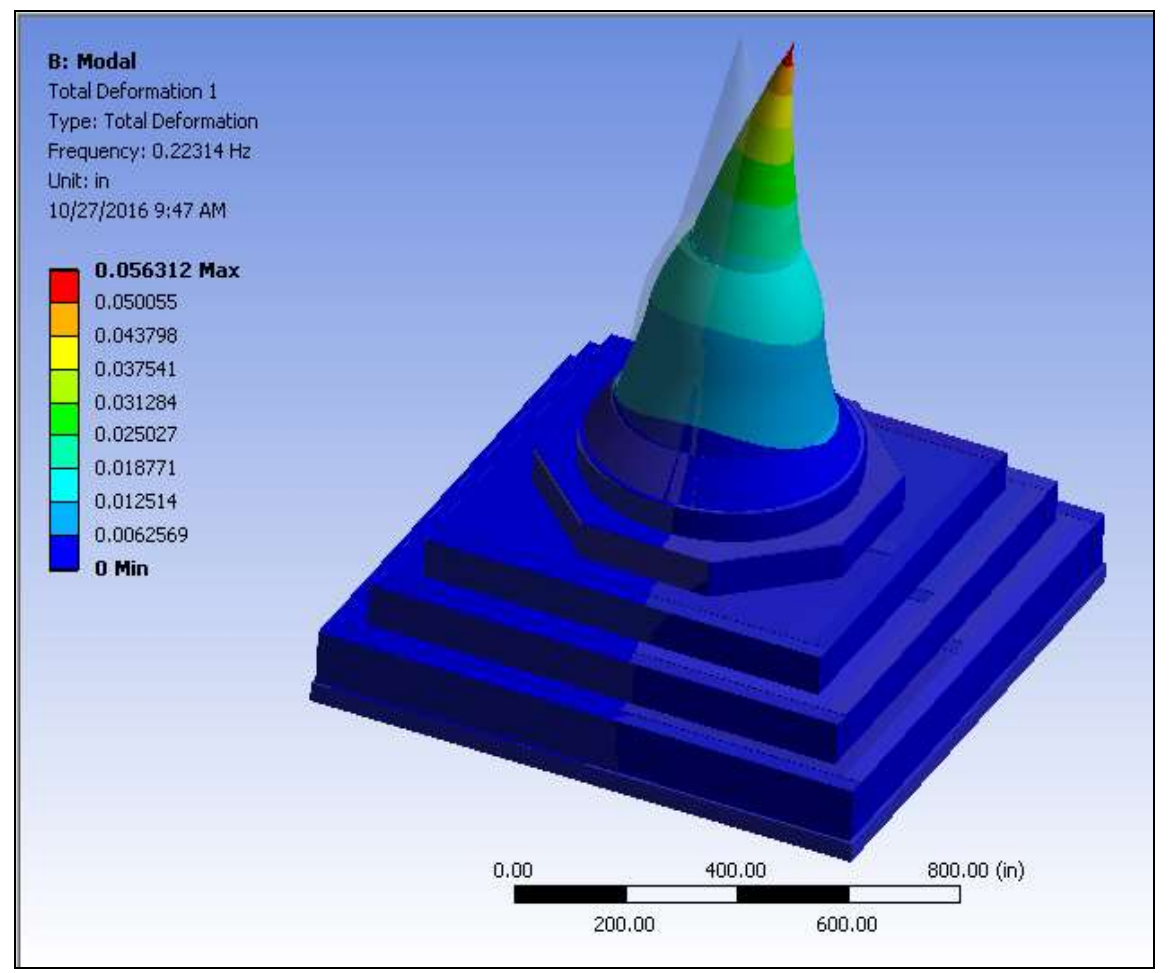

(a)

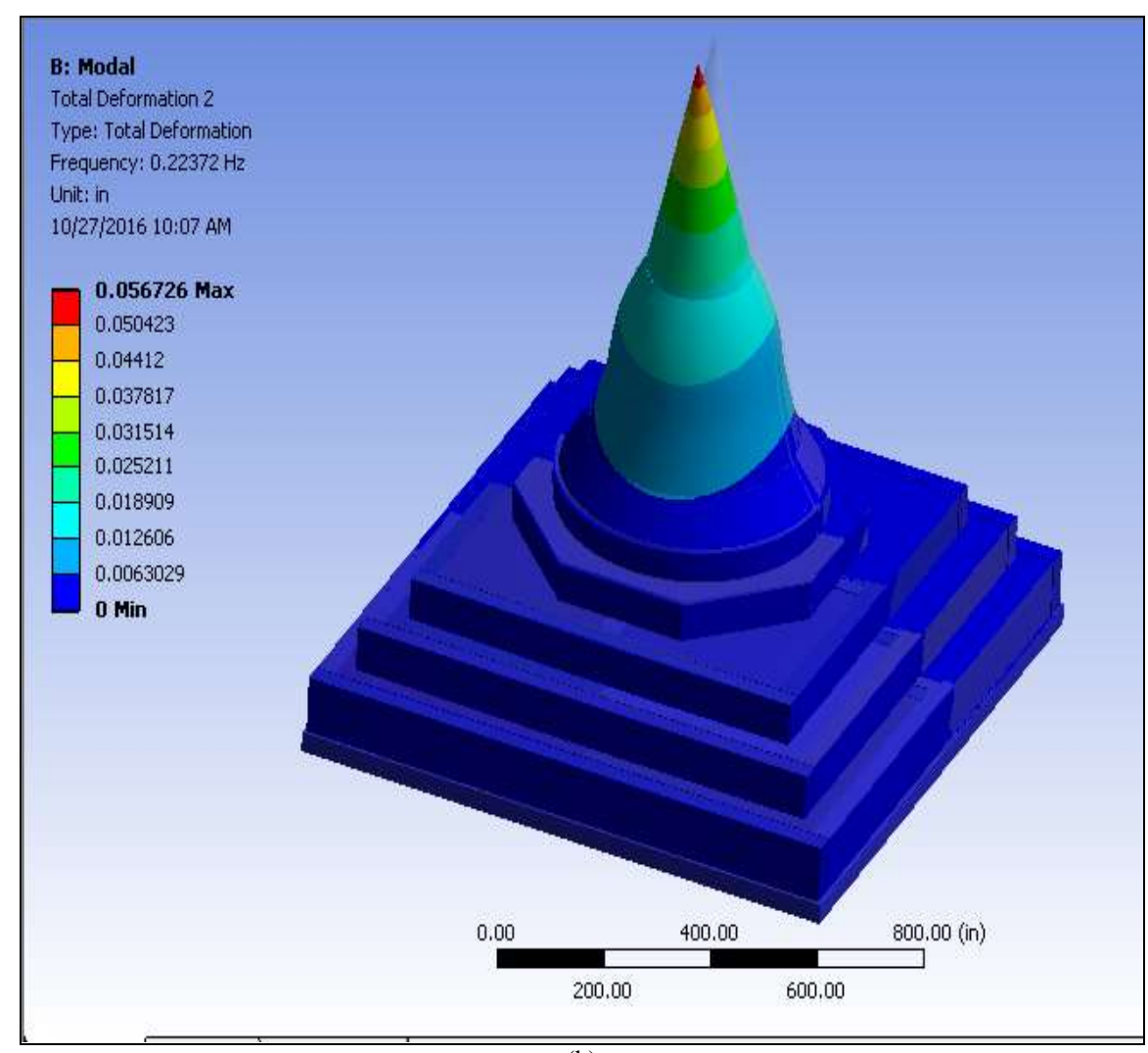

(b) 


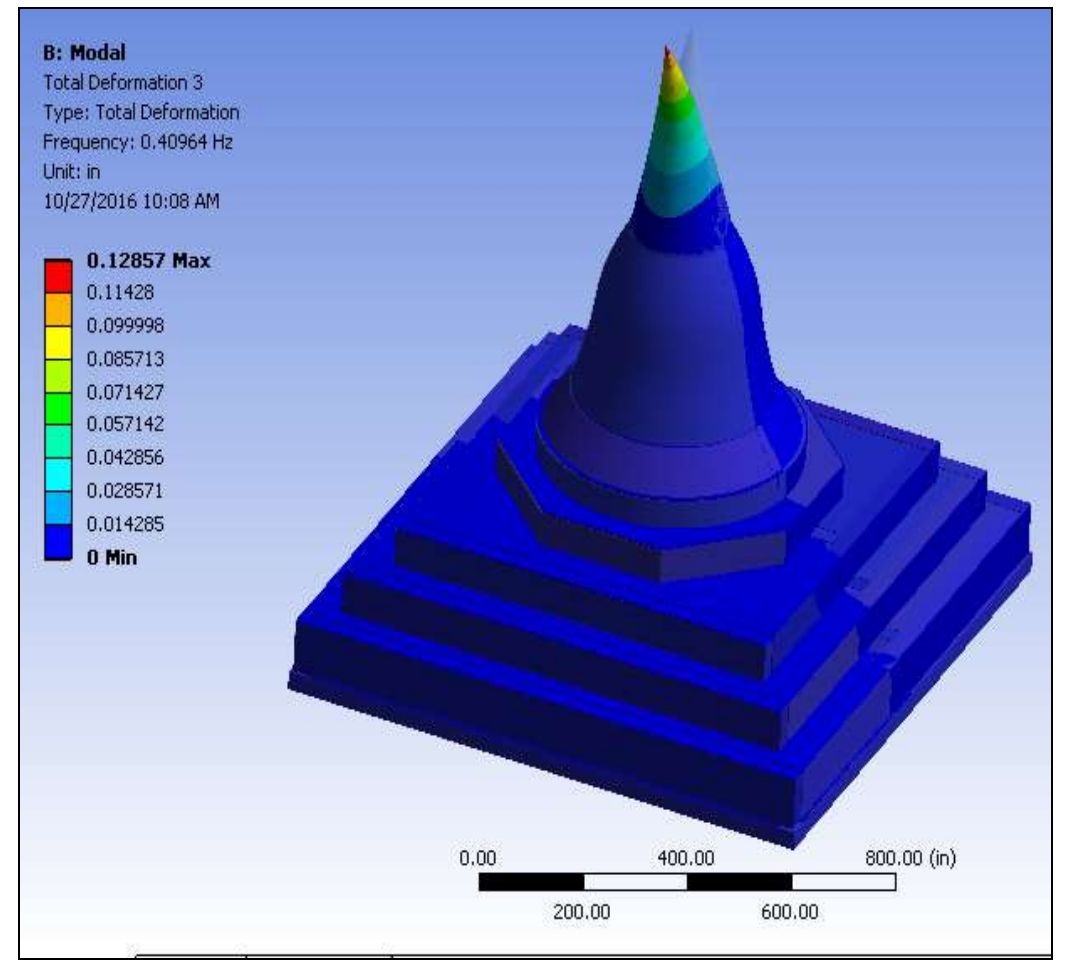

(c)

Fig.7 Mode shapes of structure for; (a) $1^{\text {st }}$ natural frequency (b) $2^{\text {nd }}$ natural frequency (c) $3^{\text {rd }}$ natural frequency

TABLE IV

NATURAL FREQUENCIES OF PROPOSED STRUCTURE

\begin{tabular}{ccc} 
Mode No & Frequency & Max Displacement (in) \\
\hline 1 & 0.22314 & $5.63 \mathrm{E}-02$ \\
2 & 0.22372 & $5.67 \mathrm{E}-02$ \\
3 & 0.40964 & 0.12857 \\
4 & 0.41081 & 0.12849 \\
5 & 0.52614 & $1.45 \mathrm{E}-02$ \\
6 & 0.54609 & $1.34 \mathrm{E}-02$ \\
7 & 0.60319 & 0.1839 \\
8 & 0.60358 & 0.18413 \\
9 & 0.89888 & $2.08 \mathrm{E}-02$ \\
10 & 0.90221 & 0.29698 \\
\hline
\end{tabular}

\section{A. Transient Analysis}

Transient dynamic analysis or time-history analysis is a technique used to determine the dynamic response of a structure under the action of any general time-dependent loads. This is used to determine the time varying displacements, stresses, strains and forces as it responds to any combination of static, transient and harmonic loads [1]. The basic equation of motion solved by a transient dynamic analysis is:

$$
\{\mathrm{F}(\mathrm{t})\}=[\mathrm{M}]\{\ddot{\mathrm{u}}\}+[\mathrm{C}]\{\dot{\mathrm{u}}\}+[\mathrm{K}]\{\mathrm{u}\}
$$

where:

[M = mass matrix

$[\mathrm{C}] \quad=$ damping matrix

$$
\begin{array}{ll}
{[\mathrm{K}]} & =\text { stiffness matrix } \\
\{. & \\
\{\mathrm{u}\} & =\text { nodal acceleration vector } \\
\dot{\mathrm{u}}\} & =\text { nodal velocity vector } \\
\{\mathrm{u}\} & =\text { nodal displacement vector } \\
\{\mathrm{F}(\mathrm{t})\} & =\text { load vector }
\end{array}
$$

Three methods are available to do transient dynamic analysis: full, mode- superposition and reduced. In this study, full transient dynamic analysis is used. It is the most general of the three methods because it allows all types of nonlinearities to be included. Once the modal analysis is completed, the next step is to carry out the transient analysis using as input, the acceleration time data of earthquake. In this study, acceleration time data consistent with $10 \%$ probability of exceedance in 50 years return period is used. From the transient analysis, it is observed that the maximum compressive stress, maximum tensile stress and maximum displacement occur between $36^{\text {th }}$ and 37 th second of the earthquake.

Under the input ground excitations, the maximum compressive stress is about $0.194 \mathrm{MPa}$ at the inverted bell shaped body. However, the maximum compressive stress is still lower than the masonry compressive strength of $3.348 \mathrm{MPa}$. The maximum tensile stress due to the earthquake excitations occurs at the middle of the top spherical cone part and is about $0.517 \mathrm{MPa}$ which is higher than the permissible tensile strength of $0.512 \mathrm{MPa}$. So if the earthquake hits, this part will be destroyed in tension failure. The general state of the stresses is shown in Fig. 8. 


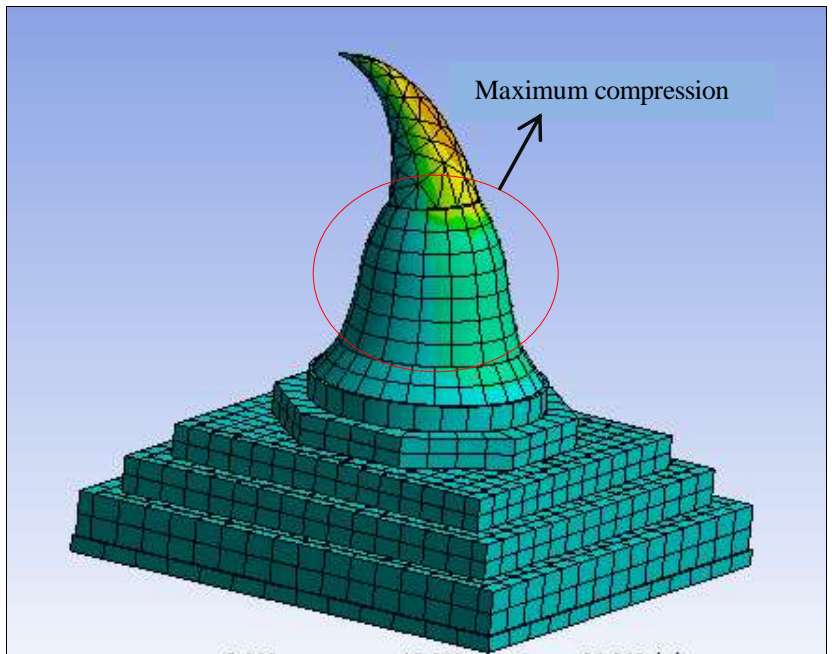

(a)

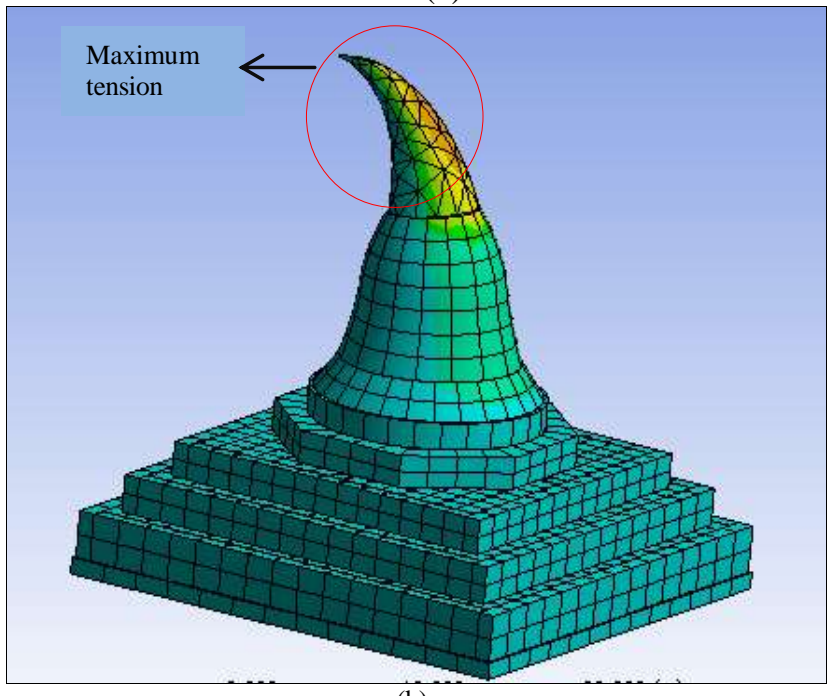

(b)

Fig.8 General stresses distribution; (a) Compression (b) Tension

The total deformation of the structure is illustrated in Fig.9. It can be seen that the maximum displacement occurs at the uppermost part of the structure with the value of 334.84 inches and the minimum occurs at the base of the structure.

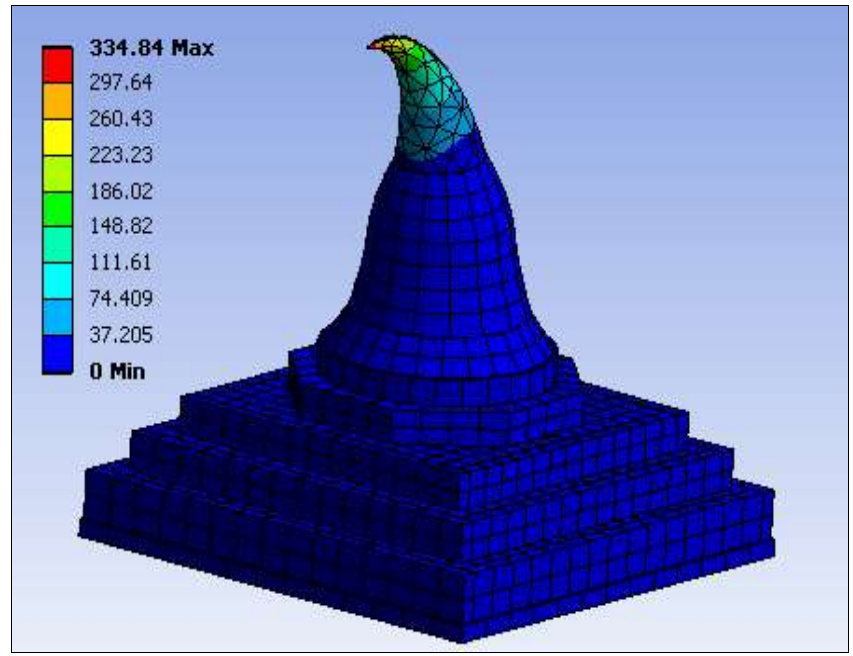

Fig. 9 Total deformation of the structure

\section{CONCLUSION}

This study presents seismic evaluation of a brick masonry cultural heritage structure located in Mandalay by using the finite element analysis. The performance of the structure is evaluated in terms of both stresses limitation and deformations. The outcome of this study showed that the structural configuration of the structure is adequate to withstand the compressive stress. However, for the tensile stress, the top of the pagoda is very sensitive to the seismic waves. It is deformed significantly and the structure is damaged by over-tensioning.

The analysis results show that the more vulnerable parts of the pagoda are inverted bell shaped portion and top spherical cone. It is suggested that retrofitting should be planned to improve the seismic resistance of those parts by means of appropriate techniques.

\section{ACKNOWLEDGMENT}

The author is deeply gratitude to Dr.Myint Thein, Rector, Mandalay Technological University, for his guidance and advice. The author would like to thank to Dr.Nilar Aye, Professor, Head of Department of Civil Engineering, Mandalay Technological University, for her kind permission, and giving useful comments. The author would like to express grateful thanks to Dr.Aye Mya Cho, Associate Professor, Department of Civil Engineering, Mandalay Technological University, for accepting and guiding through the whole period of studying for this paper, thoroughly proof-reading this paper and giving useful remarks on it.

\section{REFERENCES}

[1] ANSYS User's Manual Vol. I. Swanson Analysis Systems, Inc. 1994.

[2] ATC 1996. "Seismic Evaluation and Retrofit of Concrete Buildings", Volume 1, ATC-40 Report, Applied Technology Council, Redwood City, California.

[3] NEHRP. 1997. Guidelines for Seismic Rehabilitation of Building. FEMA 273. Federal Emergency Management Agency, Washington, D.C.

[4] Chorpa, A.K.. "Earthquake Dynamic of Structure.", arthquake Engineering Research Institute, USA, 2006.

[5] Baker, J.W. 2008. "An Introduction to Probabilistic Seismic Hazard Analysis (PSHA)". US Nuclear Regulatory Commission.

[6] Hazard Profile of Myanmar- July 2009

[7] Sirajuddin, M, Narayanan Sambu Potty and Sunil J, "Non Linear Seismic Analysis Of Masonry Structures", Journal of Design and Built Environment Vol. 9, December 2011, pp. 1-16.

[8] Myo Thant, Nwai Le` Ngal, Soe Thura Tun, Maung Thein, Win Swe and Than Myint. 2012. "Seismic Hazard Assessment for Myanmar". Myanmar Earthquake Committee (MEC) and Myanmar Geosciences Society (MGS).

[9] Michele Betti * and Luciano Galano, "Seismic Analysis of Historic Masonry Buildings: The Vicarious Palace in Pescia (Italy)",2012

[10] Chayanon Hansapinyo, "Seismic Performances of Brick Masonry Inverted Bell-Shaped Chedi ", APCBEE Procedia 9 ( 2014 ) 217 - 221. https://doi.org/10.1016/j.apcbee.2014.01.039

[11] Tint Lwin, "A Simplified Seismic Performance Based Design Method For Steel Moment Resisting Frames Using Building Design Data Bank",2015.

[12] Yoshimura, K. and Kuroki, M. (2001).Damage to masonry buildings caused by theEl Salvador earthquake of January 13, 2001,Journal of Natural Disaster Science, 23: 53-63 


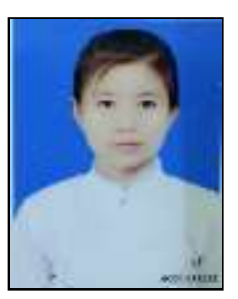

Pyin Sa Oo, A researcher in Mandalay Technological University. Holding Master degree in civil engineering from Mandalay Technological University in 2011 and currently attendiing the Doctoral study with a thesis title "optimal seismic upgrading of heritage structures in Mandalay city" and about to finish it soon. I am interested in structural engineering. 